\title{
Recycling waste plastics in roads: A life-cycle assessment study using primary data
}

\author{
J. Santos ${ }^{\text {a }}$, A. Pham ${ }^{\text {b }}$, P. Stasinopoulos ${ }^{\text {b }}$, F. Giustozzi ${ }^{\text {b,* }}$ \\ a Department of Construction Management and Engineering, University of Twente, Enschede, the Netherlands \\ b Civil and Infrastructure Engineering, RMIT University, Melbourne, Australia
}

\section{H I G H L I G H T S}

- Primary data was collected from plastic recycling companies in Australia.

- Waste plastic as polymer in bitumen produces considerable environmental benefits.

- Recycling plastics to produce synthetic asphalt aggregate is minimally beneficial.

- Recycling locally amplifies the environmental benefits of using plastics in roads.

\section{A R T I C L E I N F O}

\section{Article history:}

Received 29 June 2020

Received in revised form 17 August 2020

Accepted 19 August 2020

Available online $\mathrm{xxxx}$

Editor: Damia Barcelo

\section{Keywords:}

Life cycle assessment

Waste plastics

Asphalt pavements

Bitumen

Sustainability
GRA P H I C A L A B S T R A C T

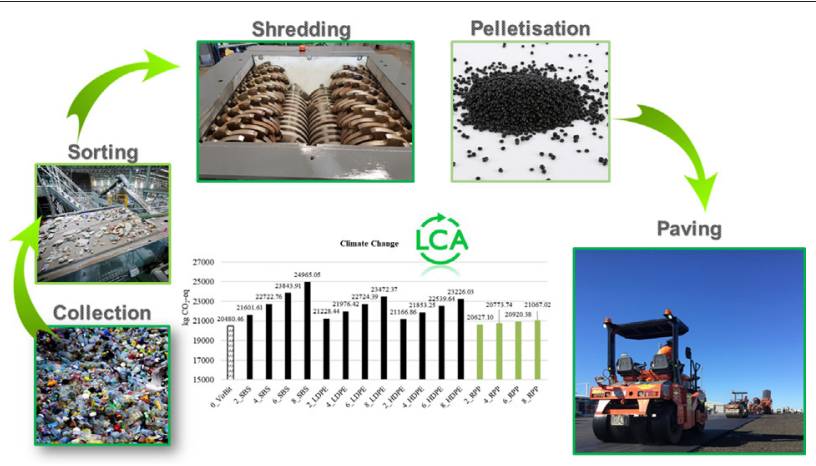

\begin{abstract}
A B S T R A C T
The present study investigates - from an environmental perspective - the processes that lead to the conversion of waste plastics into recycled plastic pellets to be used either as an additive (wet method) or as a replacement of natural aggregate (dry method) in the production of asphalt mixes. Data from recycling facilities in Victoria, Australia, were collected and used as the basis for a comparative life cycle assessment (LCA) study. Analyses were conducted by considering several replacement ratios of virgin material by its recycled counterpart in the so-called wet and dry method. A case study considering the production of recycled-plastic asphalt to be applied in the construction of a typical surface layer of a road in Victoria was evaluated. In general, the results show that recycling plastics as a polymer for bitumen modification and as a synthetic aggregate replacement in asphalt mixes has the potential to be environmentally advantageous compared to their virgin counterpart (i.e. virgin polymers and natural quarry aggregates).
\end{abstract}

(c) 2020 Elsevier B.V. All rights reserved.

\section{Introduction}

The inundation of post-consumer and post-industrial plastic waste has imposed a significant global environmental burden. For instance, in Victoria (Australia) during the biennium 2017-18, waste plastics

\footnotetext{
* Corresponding author at: RMIT University, Civil and Infrastructure Engineering, $124 \mathrm{La}$ Trobe street, Melbourne, VIC 3001, Australia.

E-mail address: filippo.giustozzi@rmit.edu.au (F. Giustozzi).
}

accounted for $585,200 \mathrm{t}$ of material, of which $448,000 \mathrm{t}$ (76.6\%) ended up in landfills while $130,000 \mathrm{t}(22.2 \%)$ were mechanically recycled and 7200 t were combusted for energy recovery. Out of the $22.2 \%$ recycled plastics, only $35 \%$ was managed domestically while $65 \%$ was exported (Locock, 2017; Infrastructure Victoria, 2019).

This panorama has boosted worldwide efforts and investments to develop the re-processing sector for recycled material, with the purpose of better enabling the use of products containing recycled materials in a variety of industries and supporting waste-to-energy sectors that 
prioritise the use of recyclable material to produce energy from the residual waste. Although different procedures have been adopted by various countries, there are still specific matters that deserve more examination. Many countries, for instance, are yet to set an overarching policy framework with recycling targets or to promote educational campaigns explaining the importance and methodology of recycling to consumers. In addition, their data collection still needs improvements to elaborate on the exact figures depicting the magnitude of the problem. Finally, within the same country or state, councils have not yet developed a consistent approach to waste collection or landfill fees.

In Australia, the National Waste Policy Action Plan (Department of Agriculture, Water and Environment, 2019) provides a comprehensive framework to identify gaps and future challenges for the waste and resource recovery sector. The first target of the policy is to ban the export of waste starting from the second half of 2020, although it has now been moved to January 2021 due to COVID disruptions. Specifically, the ban for exporting mixed plastics waste will start in July 2021 while single resins/polymer plastics will be banned from export in July 2022. This policy is expected to increase the amount of waste material that is recycled and reprocessed in Australia, which in the case of plastic stands at $12 \%$, currently. One likely consequence of such policy is the increase of local jobs, but on the other hand it will also pose significant pressure on the recycling industry and associated market of recycled products.

Road engineers, following a recent push from governments and road authorities to become more 'sustainable', have started investigating the potential reuse of waste materials, including plastics, as road pavement materials (Rahman et al., 2020). Although there are studies on similar topics since the previous century (Schroeder, 1994; Flynn, 1993; Little, 1993) and the use of 'chemically-pure' plastomeric polymers is already an established reality in many countries around the world, it is only recently that scientists have started investigating waste plastics from post-consumer and post-industrial streams as asphalt modifiers.

Previous studies have highlighted the potential mechanical benefits of using recycled plastics - mainly polyethylene due to its low melting point - as asphalt binder modifier. Among these, better resistance to high temperature deformation (rutting), greater stiffness and reduced thermal susceptibility are commonly highlighted (Ho et al., 2006; Hınıslıoğlu and Ağar, 2004; White and Reid, 2018; Bonicelli et al., 2017; Giustozzi et al., 2019). However, other studies have identified several potential challenges; some of them were related to the chemical compatibility between waste plastics and bitumen (i.e. storage stability), while others focussed more on the environmental aspects that mixing bitumen with waste plastics could pose (i.e. fuming, emissions during production, contamination and microplastics) (Heikkilä et al., 2003; Lindberg et al., 2008; Roychand and Pramanik, 2020). In particular, the topic around microplastics have generated exponential interest over the last few years (Andrady, 2017; Andersson-Sköld et al., 2020); specifically, introducing plastics in asphalt pavement layers could potentially pose environmental concerns that are worth of more research. In addition, there are growing concerns that the future recyclability of asphalt - currently $100 \%$ recyclable - could be hindered by the incorporation of waste material (Rodríguez-Fernández et al., 2020).

Nevertheless, the recent common trend in the pavement industry consists of using waste materials in road pavement applications as a response to the need of both reducing the consumption of virgin and increasingly scarce materials and avoiding landfilling (Li et al., 2019; Zhao et al., 2020). In order to quantitatively evaluate the potential environmental effects of using these waste materials in road pavement applications, several Life Cycle Assessment (LCA) studies have already been conducted (Giustozzi et al., 2012; Aurangzeb et al., 2014; Santos et al., 2015; Farina et al., 2017; Santos et al., 2018; Wang et al., 2018; Bressi et al., 2019; Praticò et al., 2020; Landi et al., 2020). However, most of them relied on the use of secondary data and models rather than primary data directly sourced at the plants. Furthermore, to the best of authors' knowledge none of them calculated the potential environmental impacts related to the production of recycled plastic pallets
(RPP) and assessed the extent to which their use in the production of asphalt mixes to be applied in the surface layer of a road pavement section might be environmental beneficial.

In order to fill this gap, the study presented in this paper investigates from an environmental perspective the processes that lead to the conversion of waste plastics into a commercial resin to be consequently used either as an additive or as a replacement of virgin aggregates for asphalt mixes production purposes. This can ultimately shed some light on whether the so called "Plastic asphalt roads" might have a positive impact on the environment in addition to some of the mechanical performance advantages commonly ascribed to this technology.

\section{Data collection}

The authors collected data from several recycling facilities in Victoria through direct visit of the plants, meetings with the management and technical departments, and online surveys. During the site visits, representatives of the companies provided site tours showing the recycling processes that take place within the facilities and explained the technology used. Specifically, three recycling facilities were visited in Victoria.

Several large-scale direct investments have been made by the Victorian Government in the recycling sector. Because many recycling facilities have commenced their business only recently (i.e. in the last two years), the quality and efficiency of the recycling machines can be considered state-of-the-art.

Among the recycling facilities in Victoria, the production rate is highly variable depending on the company size, personnel and facilities. In addition, some companies (a small portion) deal with the entire process of recycling from the initial collection of waste at the Materials Recovery Facility (MRF) to the final pelletisation. However, some other businesses look at only one specific process or service (e.g. sorting) and then cooperate with others to deliver the final recycled plastic product.

In this study the following companies were audited:

- A "sorting-only" facility that is an Australian branch of a multinational company, using the latest in sensor sorting equipment. The company deploys machines that are capable of sorting metal waste, plastic waste as well as mining material. The equipment used is capable of separating waste plastics by colour as well as by polymer type, hence favouring the efficiency of the entire recycling process.

- A "shredding and extruding-only" facility recently upgraded to process up to 12,000 t of waste plastic per year. The company utilises state-of-the-art shredders and extruders with high production rates and can reprocess all sorts of plastic, including polyethylene $(\mathrm{PE})$, polypropylene (PP), Acrylonitrile butadiene styrene (ABS) and Nylon (PA6), among others.

- An all-encompassing facility capable of taking care of almost all the different processes involved in plastic recycling, from collection at the MRFs to further separation, shredding, extrusion, and final granulation and pulverisation. The company processes approx. 15,000 $\mathrm{t}$ of waste plastic per year, mostly focusing on PP and PE.

Further details about the recycling process and machinery involved are provided in the upcoming section.

\section{Materials and methods}

The study was performed taking into account the ISO 14040/44 guidelines for LCA (ISO, 2006a; ISO, 2006b), the EN 15804:2012 (BRE, 2013) as well as the ILCD Handbook guidelines (EC-JCR-IES, 2010), whenever possible and applicable. The following subsections provide details on the considerations made in each of the four steps included in the guidelines; i.e., goal and scope definition, life cycle inventory (LCI), life cycle impact assessment (LCIA), and interpretation. 


\subsection{Goal and scope definition}

The overarching goal of the attributional product-oriented LCA study was to ascertain whether the adoption of recycled plastic pellets (RPP) in polymer-modified bitumen (PMB) and asphalt mixes is environmentally advantageous when compared to the use of chemically pure polymers and natural quarry aggregates, respectively.

In fact, waste plastics - especially plastic with a relatively low melting point (i.e. less than the asphalt mixing temperature of $165-175^{\circ} \mathrm{C}$ ) - can be used in the so called 'wet' process and mixed with hot bitumen prior to the addition of quarry aggregate. Doing so generates a polymer-network within the bitumen matrix that enhances the asphalt performance and increases the overall road pavement durability. Plastics used in the 'wet' process account for a small percentage of the overall mass of the asphalt mix, being bitumen approx. $5 \%$ of the total mix while aggregates account for the remaining $95 \%$; polymers are commonly added at 2-8\% loading (by weight of the bitumen). In this study, polyethylene-based (PE) plastics was used in the analysis due to their low melting point that makes them easy to disperse in the hot bitumen at the mixing temperature (i.e. $165-175^{\circ} \mathrm{C}$ ); specifically, low-density and high-density polyethylene were selected - melting temperature of approx. $110^{\circ} \mathrm{C}$ and $130{ }^{\circ} \mathrm{C}$, respectively. Many studies have recently investigated the effect of $\mathrm{PE}$ waste plastics as a possible bitumen modification (Singh et al., 2017; Nizamuddin et al., 2020; Joohari and Giustozzi, 2020).

The use of RPP as a substitute for the natural quarry aggregate was also evaluated. Some plastics - the ones with a relatively high melting point (i.e. above the asphalt mixing temperature) - can be used in the so called 'dry' process and mixed with aggregates prior to the addition of bitumen. The dry method basically uses synthetic plastic-made aggregate in various shapes and sizes (i.e. from pellet to powder) to replace part of the natural quarry aggregate commonly used for asphalt mixes. The waste plastics utilised in the dry process do not contribute to any enhanced behaviour of the asphalt mix but rather increase the total recyclable content of plastics due to the larger amount of aggregate in the total asphalt mix (i.e. approx. 95\% depending on the mix design).

In order to achieve these goals, three sub-goals were further considered. They were identified as follows:

1) To determine the potential environmental impacts related to the production of RPP to be used as a substitute for virgin polymer in polymer-modified bitumen.

2) To compare the potential environmental impacts associated with the use of RPP vs. chemically-pure polymers; namely, plastomers (LDPE, HDPE) and thermoplastic elastomers (SBS) in PMB according to the wet process and at various polymer loadings by weight of bitumen (i.e., $0 \%, 2 \%, 4 \%, 6 \%$ and $8 \%$ ).

3) To compare the potential environmental impacts associated with the use of RPP as replacement of the virgin aggregate from the quarry in asphalt mixes at various replacement contents (i.e., $0 \%$, $2.5 \%, 5 \%, 10 \%$ and $20 \%$ quarry aggregate replacement), in which the potential environmental impacts related to the avoided consumption of virgin aggregates are credited to the system under study.
It is also worth mentioning that the scope of the analysis did not focus on identifying the environmental hotspots within the recycling process as a first step towards improving the process of obtaining RPP. Instead, the main motivation was to ascertain the environmentally feasibility of using RPP in a pavement system. In other words, the study wanted to inform about the potential environmental impacts related to using RPP as an input in PMB blends and asphalt mixes. Therefore, this LCA study was conducted from a product-oriented perspective, rather than a process-oriented perspective (Schrijvers et al., 2020).

The results of this study are expected to provide more evidencebased data for the possible adoption of recycled materials in road standards and specifications by governing bodies, such as the Department of Transport Victoria, for enhancing the sustainability of road pavement construction practices.

To better compare between recycled materials and the corresponding virgin materials, three declared units (DUs) were defined as an alternative to the traditional functional unit (FU). The DU was used instead of the FU because (1) the number of possible applications and hence FUs of the RPP is very large, (2) the studied materials might not present the same performance throughout the pavement life cycle, and (3) the gate-to-gate and cradle-to-gate approaches of the LCA studies performed do not cover a full life cycle (EC-JCR-IES, 2010; BRE, 2013).

1) DU1: provision of $1 \mathrm{t}$ of RPP produced in a recycling facility.

2) DU2: provision of the quantity of PMB produced with different RPP content (i.e. $0 \%, 2 \%, 4 \%, 6 \%$ and $8 \%$ ) (wet process) to be applied in a road pavement section with the characteristics described in Table 1.

3) DU3: provision of the quantity of asphalt mix produced with different recycled plastics aggregate replacements (i.e. $0 \%, 2.5 \%, 5 \%, 10 \%$ and $20 \%$ ) (dry process) to be applied in a road pavement section with the characteristics described in Table 1.

Based on the data presented in Table 1, the quantities of virgin polymers (plastomers and SBS) and RPP applied in PMB and asphalt mix alternatives were calculated and presented in Table 2 . Hereafter, the 16 PMB alternatives studied for the wet method are named according to the nomenclature "X_Y" where " $\mathrm{X}$ " stands for the polymer load by mass of bitumen (i.e. $0 \%, 2 \%, 4 \%, 6 \%$ and $8 \%$ ) and "Y" represents the type polymer (i.e. either recycled or virgin). Moreover, because there is no "road-grade" type of plastic in Victoria, it is assumed that the recycled plastics for the wet method can alternatively belong to the waste LDPE or waste HDPE sub-types.

As far as the dry method is concerned, an analogous "X_Y" nomenclature is adopted, where " $\mathrm{X}$ " stands for the replacement content of virgin aggregates (i.e. 0\%, 2.5\%, 5\%, 10\% and 20\%) and "Y" represents the type of aggregates (i.e. either recycled (RPP) or virgin (VirAggreg)).

The geographical scope of the study was Victoria, Australia, and the temporal scope was 2019. The system boundaries for the analysis of the plastic recycling system were defined from the moment the waste plastic arrived at the materials recovery facility (MRF) until the moment the RPP were made available for use in PMB (wet method) and PMA mixes (dry method). This excludes the collection phase (i.e. kerbside collection) and the transport between collection points and the MRF.

Table 1

Characteristics of the road pavement section in which the asphalt surface layer is made using PMB produced with different RPP contents (i.e. $0 \%, 2 \%, 4 \%, 6 \%$ and $8 \%$ ).

\begin{tabular}{|c|c|c|c|}
\hline Item & Value & Unit & Note \\
\hline Lane width & 3.5 & $\mathrm{~m}$ & *standard lane width in Australia \\
\hline Road length & 1000 & $\mathrm{~m}$ & - \\
\hline Asphalt surface layer thickness & 0.04 & $\mathrm{~m}$ & ${ }^{*}$ common value for resurfacing works in Australia \\
\hline Asphalt surface layer volume & 140 & $\mathrm{~m}^{3}$ & \\
\hline Density of compacted asphalt mixture & 2450 & $\mathrm{~kg} / \mathrm{m}^{3}$ & *typical density of asphalt surface mixture \\
\hline Mass of asphalt mix & 343 & tonnes & - \\
\hline Mass of bitumen & 17.15 & tonnes & Approx. $5 \%$ by mass of asphalt \\
\hline Mass of polymer & $0-1.37$ & tonnes & For polymer content ranging between 0 and $8 \%$ by mass of bitumen \\
\hline Mass of aggregate replacement & $0-65.17$ & tonnes & Aggregate replacement ranging from 0 to $20 \%$ by mass of virgin aggregates \\
\hline
\end{tabular}


Table 2

Mass of the components making up the recycled PMB alternatives and PMA mixes with waste plastics.

\begin{tabular}{|c|c|c|c|c|c|c|}
\hline & \multirow[t]{2}{*}{ Item } & \multicolumn{5}{|c|}{ Polymer (wet method) } \\
\hline & & $0 \%$ & $2 \%$ & $4 \%$ & $6 \%$ & $8 \%$ \\
\hline \multirow{6}{*}{$\begin{array}{l}\text { WET Method } \\
\text { (RPP as a polymer in bitumen) }\end{array}$} & Virgin thermoplastic elastomers (i.e. SBS) (tonnes) & 0 & 0.343 & 0.686 & 1.029 & 1.372 \\
\hline & Recycled low-melting point plastic pellets (tonnes) & & & & & \\
\hline & Virgin plastomers (i.e. LDPE or HDPE) (tonnes) & & & & & \\
\hline & Bitumen (tonnes) & 17.15 & & & & \\
\hline & \multirow[t]{2}{*}{ Item } & \multicolumn{5}{|c|}{ Aggregate (dry method) } \\
\hline & & $0 \%$ & $2.5 \%$ & $5 \%$ & $10 \%$ & $20 \%$ \\
\hline \multirow[t]{2}{*}{ DRY Method (RPP as an aggregate) } & Recycled high-melting point plastic pellets (tonnes) & 0 & 8.15 & 16.29 & 32.59 & 65.17 \\
\hline & Virgin quarry aggregate (tonnes) & 325.85 & 317.70 & 309.56 & 293.27 & 260.68 \\
\hline
\end{tabular}

In particular, the analysis accounted for the production of energy and material resources and the direct emissions occurring to air, water and soil during the waste management phase, i.e. production of recycled plastic, as well as during the production of the virgin materials used alternatively. The main recycling processes and sub-processes considered in the system boundaries and associated inputs and outputs are shown in Fig. 1 and include (1) the sorting of waste plastic, (2) shredding, and (3) pelletisation. They are described in more detail in the next sections. In turn, the processes involved in the production of the asphalt mixes with different recycled plastics aggregate replacements are depicted in Fig. 2. They include the production of the raw materials required to produce the asphalt mixes, their transportation to the mixing plant through heavy vehicles and the production of the asphalt mixes. As far as the production of the asphalt mixes is concerned, it was considered that all mixes were produced through a conventional batch mix plant. The fuel consumed by the wheel loader and the electricity consumed by the electric group of the asphalt plant were also taken into account.

Furthermore, the methodological aspects related to the distribution of the burdens resulting from the production of virgin and recycled materials (i.e. aggregates and RPP, respectively), and the credits from the avoided production of virgin aggregates was addressed according to the
100:100 approach (Allacker et al., 2017), assuming equal quality between recycled and virgin materials, or in other words a replacement ratio of 1:1.

Although the foreground processes were modelled by using primary data provided by the audited companies and the background processes through certified and reliable LCI databases, the following assumptions were made about the system boundaries:

1) capital goods of the foreground processes - such as the construction of the MRF and its maintenance - were excluded;

2 ) the processes referring to the disposal of the waste products generated during the pelletisation (e.g. incineration, landfill, etc.) were also excluded. This modelling choice was motivated by the small quantity of recycling waste as well as the variability of the actual fate to be given to waste material.

\subsection{Life cycle inventory and assumptions}

The life cycle inventory analysis is the process of collecting the primary and secondary data required to quantify the identified physical inputs and outputs associated with the processes taking place within the system boundary of the entire product system.

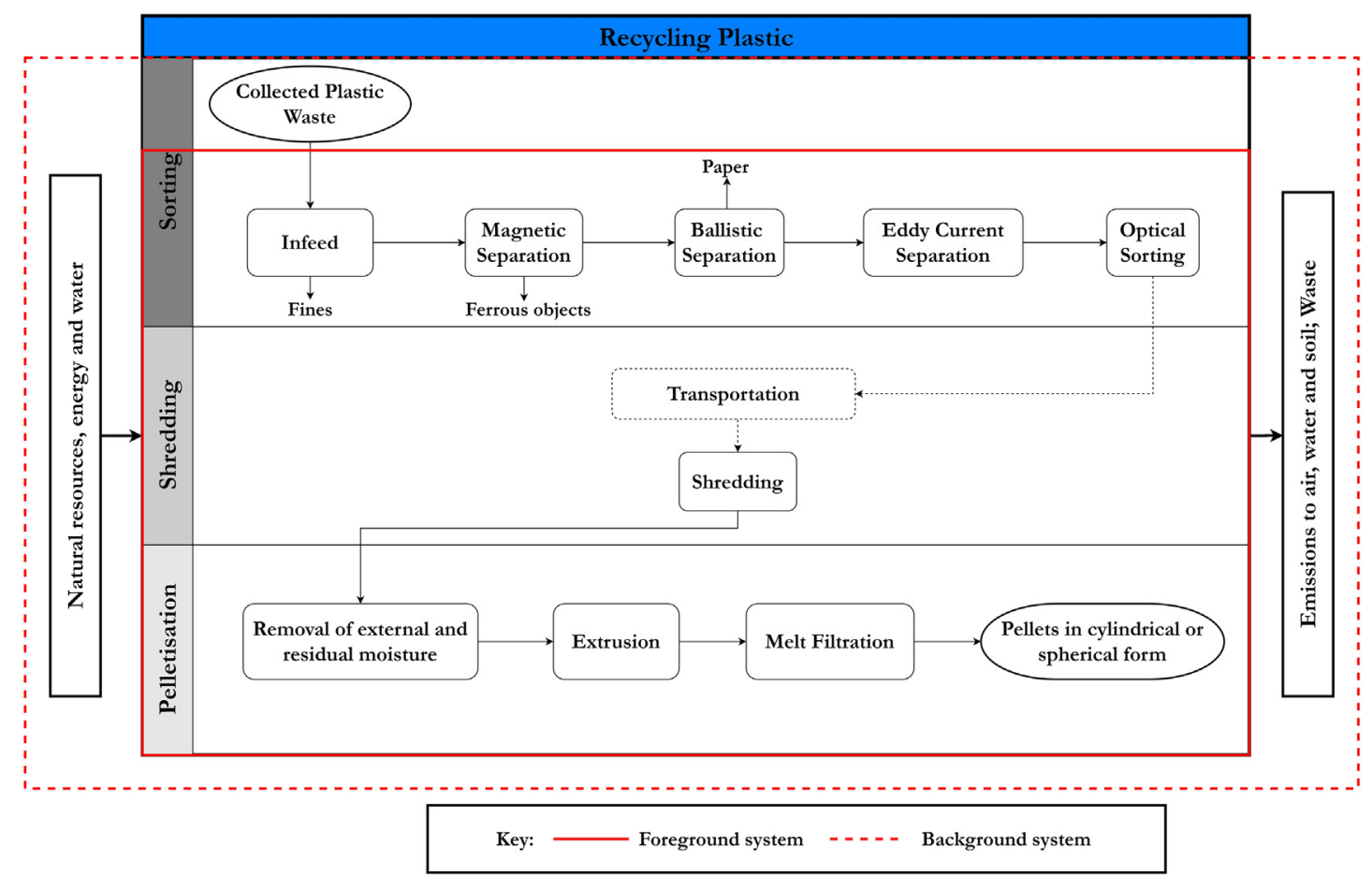

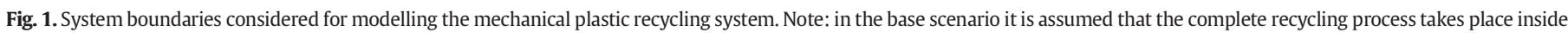
the same facility. Therefore, the transportation process depicted in the shredding phase with the dash line does not occur. 


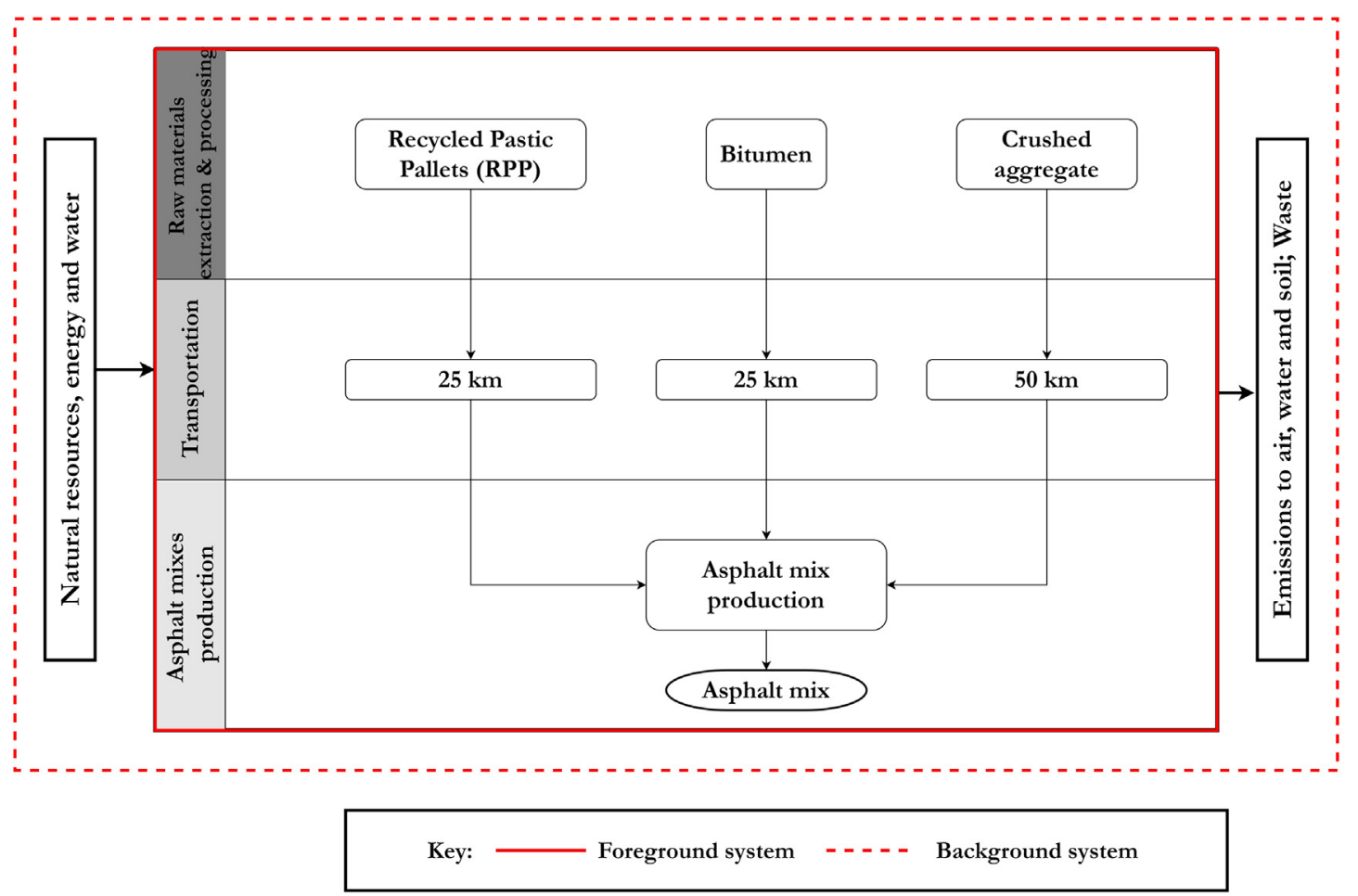

Fig. 2. System boundaries considered for modelling the production of asphalt mixes.

Foreground data used in the study was primary and sourced from the three Australian companies specialised in different stages of recycling plastics. A combination of site visits, technical meetings with the companies' representatives and email correspondence was used to engage with the aforementioned companies. During these site visits, representatives of the companies provided the authors with a demonstration of the technologies used within the facility and specific information (i.e. brand/model of the machines, production rates, inputs and outputs). This information was later complemented with the data obtained from technical data sheets of relevant technologies and equipment used at the respective companies. In turn, the background data were sourced from the AusLCI database. The same database was also used to model the production of the virgin materials used as counterpart to the RPP applied in PMB and asphalt mixes (i.e. virgin aggregate, chemically pure plastomers - LDPE/HDPE - and thermoplastic elastomers - SBS).

Details on the operational data and related assumptions considered for modelling the mechanical plastic recycling system are given in the following subsections.

\subsubsection{Collection}

The collection of waste plastics occurs primarily at three levels: municipal, commercial and industrial. The primary activities within this process predominantly consists of transportation. Several organisations collect items such as packaging film, milk crates, polyethylene pipes, plastic drums and wheelie bins. Due to the multiplicity of collection points and distances involved in the collection, this process was not included within the system boundaries of the analysis. In addition, the scheduling of the service is highly variable and dependent on demand and other external events that are difficult to predict (i.e. government incentive schemes).

\subsubsection{Sorting}

Because of the diversity of plastics collected, the municipal collection is generally transported to an MRF for sorting. The plastics that are collected from commercial and industrial businesses have less variations.
For instance, if a line of defective milk crates is collected, the type of plastic would be uniform across the line collected.

At the MRF, the collected plastic waste goes through different sorting processes involving different types of sorting machines. It starts with the collected waste being fed through the sorting machine via a conveyor belt (i.e. Steinert BMG). A combination of an overband magnet (a type of magnetic separator) and a magnetic head pulley (a separator of ferromagnetic particles) collects and separates ferrous objects. In turn, a ballistic separator mechanically sorts through rolling fractions (e.g. plastics and glass) and flat fractions (e.g. cardboards, newspapers and old corrugated cardboards). The rolling fraction is then passed through an eddy current separator where non-ferrous metals (e.g. aluminium cans) are separated from the waste plastic materials by a powerful magnetic field. The remaining waste consists of mixed plastics and goes through an optical sorter unit (i.e. Steinert Unisort). The machine at the plant comprised a Near Infra-Red (NIR) camera technology with Hyper Spectral Imaging. NIR refers to a spectrum where wavelengths typically range between $760 \mathrm{~nm}$ and $2500 \mathrm{~nm}$. Upon contact with the mixed waste, the NIR wavelengths emit specific molecular vibrations that, when detected, indicates a specific chemical composition. The sorting machine can work with particles ranging between 40 and $300 \mathrm{~mm}$ and can sort through various types of plastic, such as PET, PS, PVC, PP and PE. The remainder of plastic is then sorted to a "mixed plastic" category. Although the average composition of the plastics being collected is different every time and depends upon the specific country and its policies, the majority of the waste plastics stream in Victoria (Australia) are class 2 and 4 (HDPE and LDPE, respectively) followed by high-melting point plastics such as class 1 (PET) and class 5 (PP).

The primary inputs of the sorting process include the collected plastic waste, electricity, compressed air and a conveyor belt. The components of the optical sorter unit include a magnet, ballistic separator, optical sorters and an eddy current separator.

\subsubsection{Shredding}

In this process, a single-shaft shredding machine (i.e. Lindner Micromat) is used to shred the incoming plastic waste in such a way 
that the produced output ranges between $15 \mathrm{~mm}$ and $100 \mathrm{~mm}$. The cutting chamber volume can accommodate up to $5.6 \mathrm{~m}^{3}$ of waste plastics when running at full capacity. The primary components of this machine are a hydraulic maintenance door, a gear or belt drive, an internal pusher, a cutting system and a screen unit. It is common practice in a recycling plant to designate multiple shredding machines to different types of infeed. For instance, it is not unusual to find a designated shredder for LDPE films and packaging and a shredder for bulky waste plastics.

\subsubsection{Pelletisation}

The pelletisation process starts with the shredded plastic (flakes) being placed within one or two hoppers that are fed through a vacuum sluice into a vacuum reactor further divided in three zones. In the first zone, the plastic flakes are stripped of external moisture. In the second zone, the temperature is increased to $190^{\circ} \mathrm{C}$ and finally, in the third zone, the removal of internal moisture and decontamination occurs. The plastic is then fed into a single-screw extruder at high vacuum where the flakes are melted by the heat generated from the barrels.

Following extrusion, the plastic is filtered through a $32 \mu \mathrm{m}$ mesh screen to remove potential contaminants and the melted material is passed through to become pellets. Occasionally, when a line requires it, a colouring pigment (i.e. masterbatch) can also be used. For the purposes of recycled plastic for asphalt mixes, no masterbatch is required.

The inputs of the pelletisation process include shredded plastic flakes, generally categorised in their respective types (i.e. HDPE, LDPE, PET, PP), electricity and water.

\subsubsection{Inventory data}

The information about the type and quantity of inputs and outputs related to the main processes taking place at the recycling plant as well as the corresponding processes retrieved from the AusLCI database are presented in Table 3. Table 4 presents the AusLCI database processes adopted for modelling the production of the virgin materials used in PMB alternatives. Table 5 shows the input inventory to produce $1 \mathrm{t}$ of asphalt mix.

\section{Table 3}

Inventory of the type and quantity of inputs and outputs related to the main processes taking place at the recycling facility as well as the corresponding processes retrieved from the AusLCI database.

\begin{tabular}{|c|c|c|c|}
\hline Process & Unit & Value & $\begin{array}{l}\text { Process taken from the AusLCI } \\
\text { database }\end{array}$ \\
\hline \multicolumn{4}{|l|}{ Sorting } \\
\hline Electricity & kWh & 11.956 & Electricity, low voltage, Victoria \\
\hline $\begin{array}{l}\text { Recycled plastic collected } \\
\text { Output }\end{array}$ & tonne & 1.718 & - \\
\hline Other Sorted Products & tonne & 0.697 & - \\
\hline Recycled plastic sorted & tonne & 1.020 & - \\
\hline \multicolumn{4}{|l|}{ Shredding } \\
\hline Electricity & kWh & 11.224 & Electricity, low voltage, Victoria \\
\hline $\begin{array}{l}\text { Recycled plastic sorted } \\
\text { Output }\end{array}$ & tonne & 1.020 & - \\
\hline Recycled plastic shredded & tonne & 1.020 & - \\
\hline \multicolumn{4}{|l|}{ Pelletisation } \\
\hline Electricity & kWh & 301 & Electricity, low voltage, Victoria \\
\hline Water & 1 & 136 & Tap water, at user \\
\hline $\begin{array}{l}\text { Recycled plastic shredded } \\
\text { Output }\end{array}$ & tonne & 1.020 & - \\
\hline Pelletisation waste & $\mathrm{kg}$ & 20 & - \\
\hline Recycled plastic pellets (RPP) & tonne & 1 & - \\
\hline
\end{tabular}

Note: the values reported in this table are based on a mass allocation.
Table 4

AusLCI database processes adopted to model the production of the virgin materials used for the several PMB alternatives.

\begin{tabular}{llc}
\hline Material & Process name & Unit \\
\hline SBS & Synthetic rubber, at plant & $\mathrm{kg}$ \\
LDPE & Polyethylene, LDPE, granulate, at plant & $\mathrm{kg}$ \\
HPDE & Polyethylene, HDPE, granulate, at plant & $\mathrm{kg}$ \\
\hline
\end{tabular}

\subsection{Alternative scenarios definition}

The modelling of the system described in the previous sections relies on the assumption that all the processes required to transform plastic waste into RPP take place within the same facility. While this is true in the case of one of the audited companies (see Section 2), the others two were of the type "sorting-only facility" and "shredding and extruding-only facility". That means that the complete recycling process requires the movement of materials between the two types of companies. In order to account for this fact, a scenario analysis was performed that considers the transportation of sorted plastic by trucks between companies according to two real transportation distances estimated with Google Maps: i) $28 \mathrm{~km}$ (hereafter named AS1) and ii) $125 \mathrm{~km}$ (hereafter named AS2).

\subsection{Impact assessment}

Based on the Best Practice Guide for Mid-Point Life Cycle Impact Assessment in Australia (Renouf et al., 2015), the potential environmental impacts were estimated according to the CML baseline impact assessment method (Guinee et al., 2002), version 4.4. of January 2015. In particular, the following impact categories were considered: climate change (CC), acidification (Ac), eutrophication (Eu), ozone layer depletion (OD) and photochemical oxidation (PO). No normalisation and weighting were further performed. Finally, the LCA modelling was undertaken with the openLCA software version 1.8.0 (GreenDelta, 2016).

\section{Results}

\subsection{Declared unit 1}

The characterized impact scores for all considered impact categories are shown in Table 6. Fig. 3 displays the relative contribution of the main processes to the impact categories scores. As it can be observed, the potential environmental impact scores are mostly driven by the pelletisation process. On average, it contributes to $93 \%$ of the total score. Such results are essentially due to the production of the electricity consumed to power this process. In turn, the sorting and shredding processes claim a similar and low contribution (i.e. approx. 3.5\%) to the characterized impact scores.

\subsection{Declared unit 2}

The characterized impact scores associated with the production of PMB to be used in the construction of the surface layer of a road pavement section with the characteristics presented in Table 1 are illustrated in Fig. 4 per impact category.

When analysing the environmental effects arising from the replacement of virgin polymers (i.e. SBS, LDPE or HDPE) by RPP in the production of PMB, Fig. 4 shows that - for the conditions and assumptions considered in this case study - this decision is always environmentally preferable, regardless of the specific type of virgin polymer being replaced.

Overall, the greatest environmental benefits are obtained when RPP are used in lieu of SBS. The lowest reductions in the environmental impact scores are observed for the impact category PO (4.5-8.6\%). This is 
Table 5

Input inventory to produce $1 \mathrm{t}$ of asphalt mix.

\begin{tabular}{|c|c|c|c|}
\hline Flow & Unit & Amount & Note \\
\hline Diesel, burned in building machine & MJ & 8.49 & - \\
\hline Electricity, low voltage, Victoria & kWh & 6.0 & - \\
\hline Natural gas, high pressure, at consumer & MJ & 300.0 & - \\
\hline Tap water, at user & $\mathrm{kg}$ & 5.0 & - \\
\hline Gravel, crushed, at mine & tonne & $0.95-\%$ RPP & $\%$ RPP can have the following values: $0,0.025,0.05,0.1$ and 0.2 \\
\hline Transport, truck, 16 to $28 \mathrm{t}$, fleet average & tonne*km & 50 & Aggregates transportation \\
\hline Bitumen, at refinery & tonne & 0.05 & - \\
\hline Transport, truck, 16 to $28 \mathrm{t}$, fleet average & tonne*km & 25 & Bitumen transportation \\
\hline Recycled plastic pellets (RPP) & tonne & \%_RPP & Values presented above \\
\hline Transport, truck, 16 to $28 \mathrm{t}$, fleet average & tonne*km & 25 & RPP transportation \\
\hline
\end{tabular}

Table 6

Potential environmental impact scores for producing $1 \mathrm{t}$ of recycled plastic pellets (RPP).

\begin{tabular}{lll}
\hline Impact category & Unit & Value \\
\hline $\mathrm{Ac}$ & $\mathrm{kg} \mathrm{SO}_{2}$-eq & $3,47 \mathrm{E}-02$ \\
$\mathrm{Eu}$ & $\mathrm{kg} \mathrm{PO}_{\text {-eq }}$ & $4,50 \mathrm{E}-02$ \\
$\mathrm{CC}$ & $\mathrm{kg} \mathrm{CO}_{2}$-eq & $4,28 \mathrm{E}+02$ \\
$\mathrm{OD}$ & $\mathrm{kg} \mathrm{CFC}_{11}$-eq & $1,59 \mathrm{E}-07$ \\
$\mathrm{PO}$ & $\mathrm{kg} \mathrm{C}_{2} \mathrm{H}_{4}$-eq & $1,92 \mathrm{E}-03$ \\
\hline
\end{tabular}

Key: Ac- acidification; Eu- eutrophication; CC- climate change; OD- ozone layer depletion; PO- photochemical oxidation.

closely followed by the impact category Ac (4.7-8.9\%) and contrasts with the reductions observed for the impact category CC (8.6-15.6\%), which were found to be the most expressive, followed by those achieved for the impact category OD (7.2-13.4\%).

When comparing RPP and virgin plastomers (i.e. LDPE and HDPE), Fig. 4 shows that except for the impact category PO, producing virgin LDPE yields the highest environmental impact scores. Thus, using RPP as an alternative polymer to their virgin plastomeric counterparts reduces the impact scores by as much as $11.7 \%$ (impact category PO for HDPE). This value is attenuated for the impact category OD, with almost neglectable reductions (in the range of $0.003-0.01 \%$ ) for both types of virgin plastomers.

Finally, it is worth mentioning that for the system boundaries considered in this case study, the use of PMB is always more environmentally burdensome than the standard bitumen (referred in Fig. 4 as $0 \_$VirBit). This consequence arises from the fact that the asphalt binder modification implies the consumption of at least one additional material, whether it is a virgin or recycled polymer. Environmental benefits, however, are expected to be observed in other pavement life cycle phases thanks to a general reduction of pavement permanent deformation, better resistance to fatigue and greater adhesion between asphalt binder and aggregates over the service life (Zhu et al., 2014). Nevertheless, the study of the environmental impacts related to those effects falls out of the scope of this research study, which mainly focussed on recycling waste plastics in roads.

\subsection{Declared unit 3}

The characterized impact scores associated with the production of asphalt mixes containing different contents of recycled plastics aggregate (i.e. $0 \%, 2.5 \%, 5 \%, 10 \%$ and $20 \%$ ) to be used in the construction of the surface layer of a road pavement section with the characteristics presented in Table 1 are depicted in Fig. 5 per impact category.

For the conditions considered in this case study, the results shown in Fig. 5 indicate that the use of asphalt wearing courses containing asphalt mixes where virgin quarry aggregates are partially replaced by RPP is, in general, only minimally beneficial to the environment. Despite being tenuous, this benefit translates into a reduction in the score of the impact categories AC, OD, PO that amounts to approximately $2 \%$ in the case of the highest replacement rate (i.e. 20\%).

The exceptions to this common trend across the majority of the impact categories are observed for impact categories $\mathrm{CC}$ and $\mathrm{Eu}$, for which the impact scores are likely to increase by as much as approximately $159 \%$ (in the case of the impact category CC and asphalt mix 20_RPP)

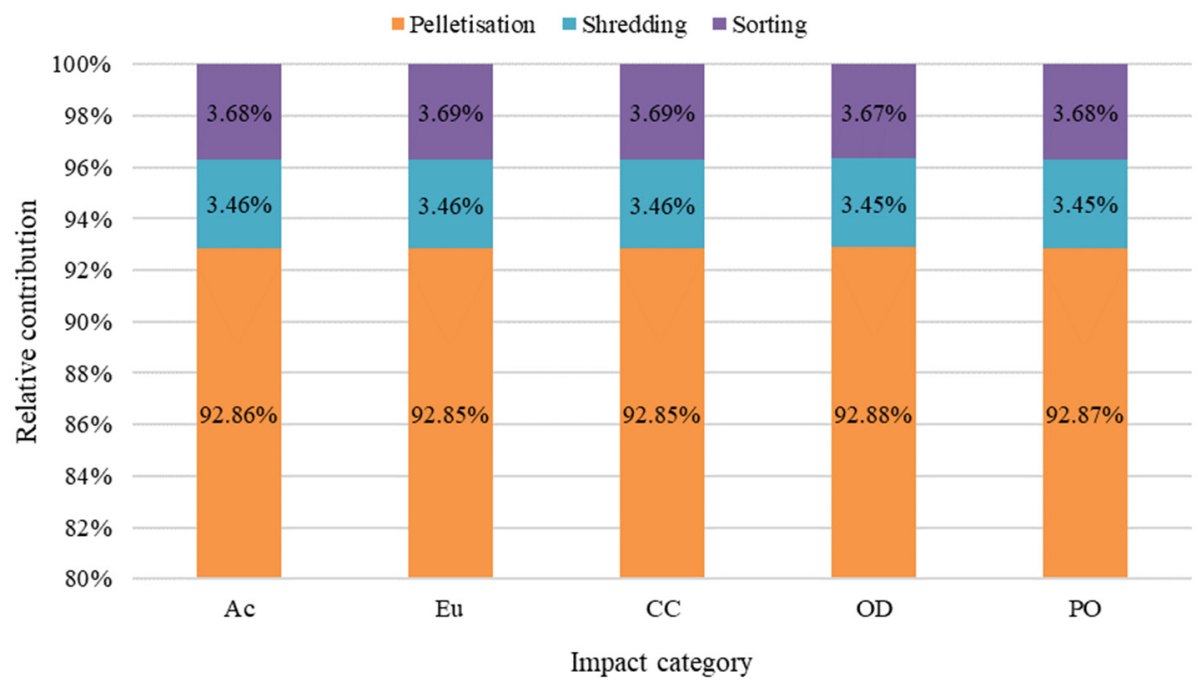

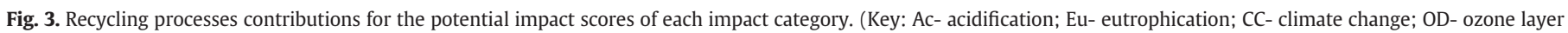
depletion; PO- photochemical oxidation). 


\section{Acidification}

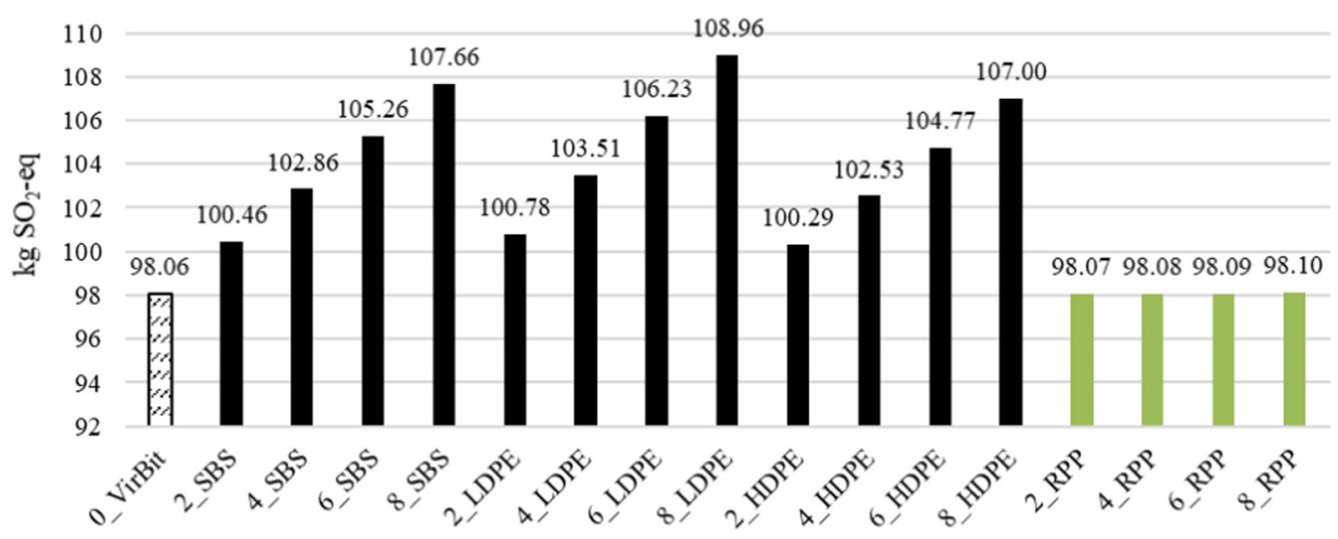

(a)

\section{Eutrophication}

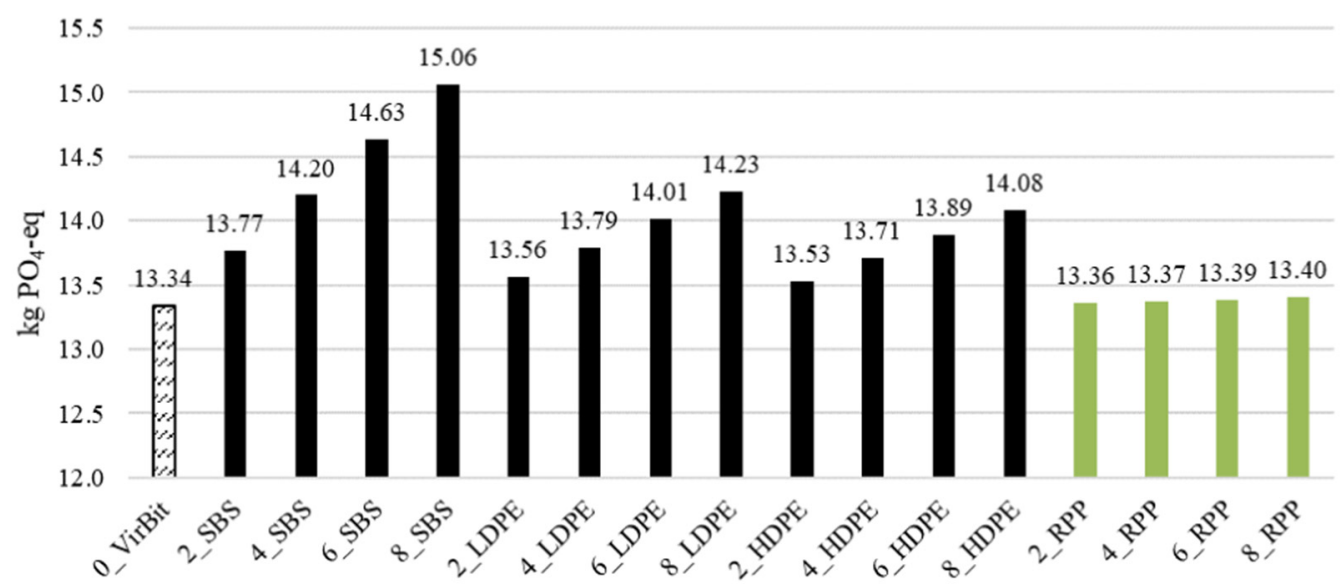

(b)

\section{Climate Change}

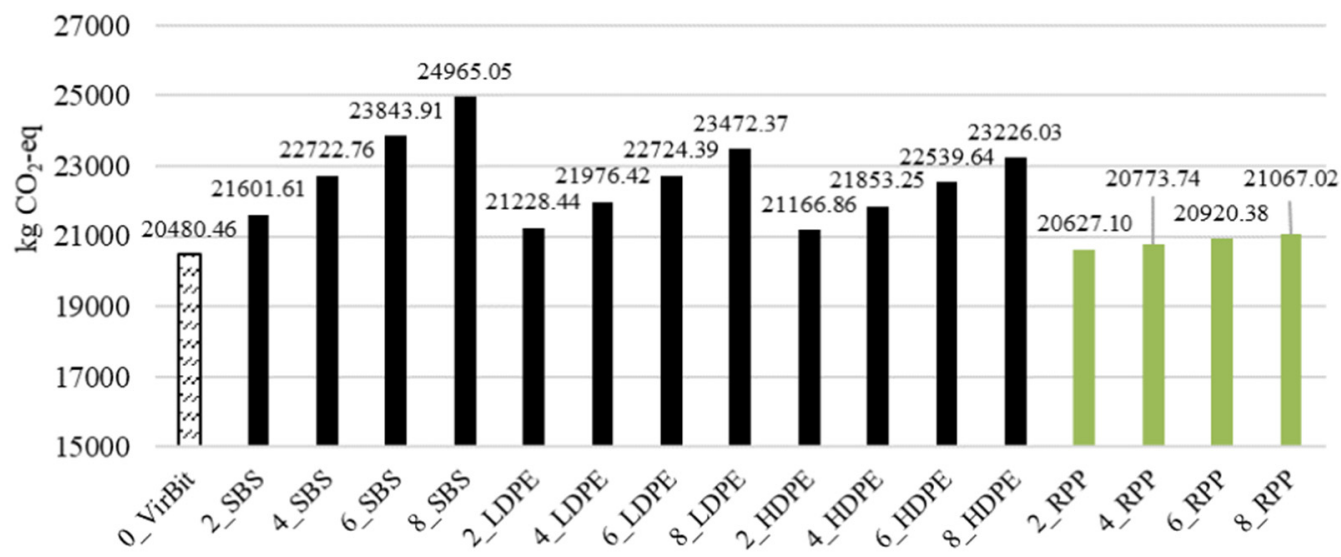

(c)

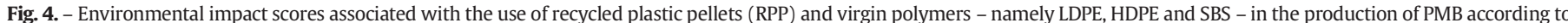

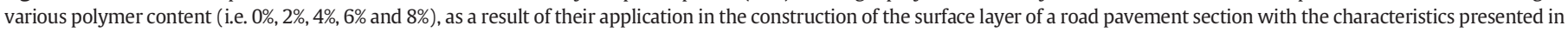
Table 1. (Key: VirBit - virgin bitumen; SBS- styrene butadiene styrene; LDPE- low-density polyethylene; HDPE- high-density polyethylene; RPP- recycled plastic pallets). 


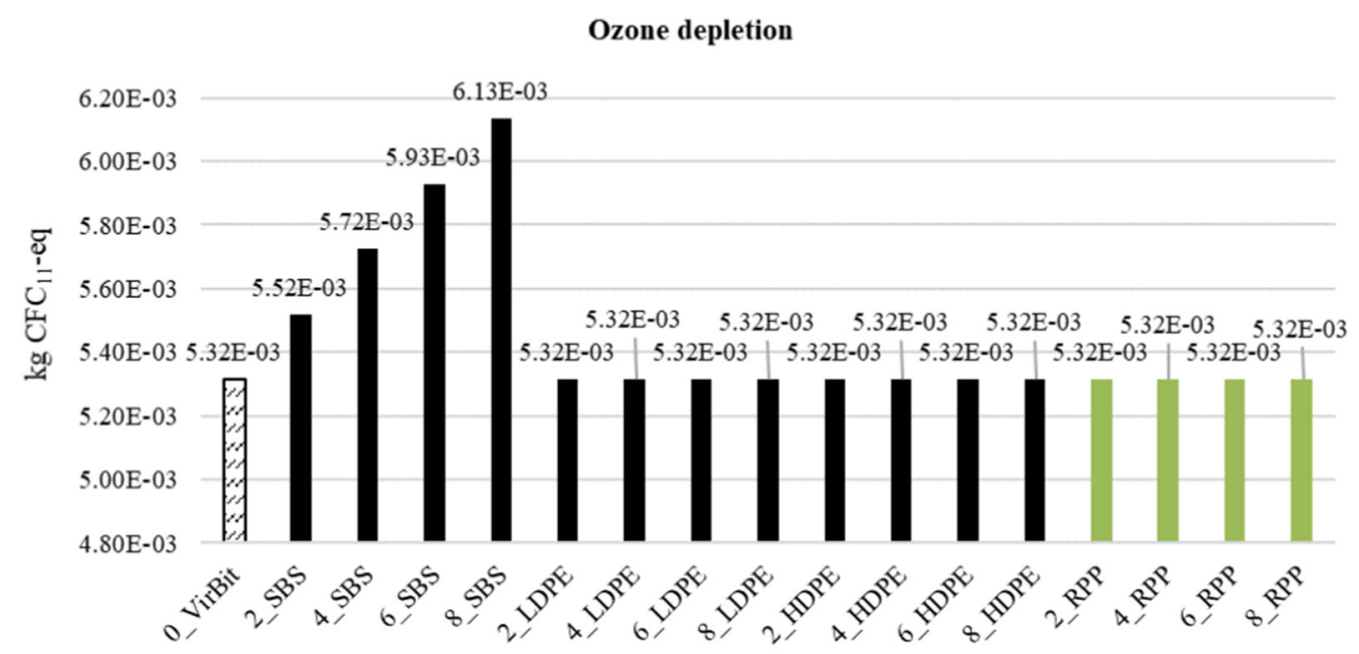

(d)

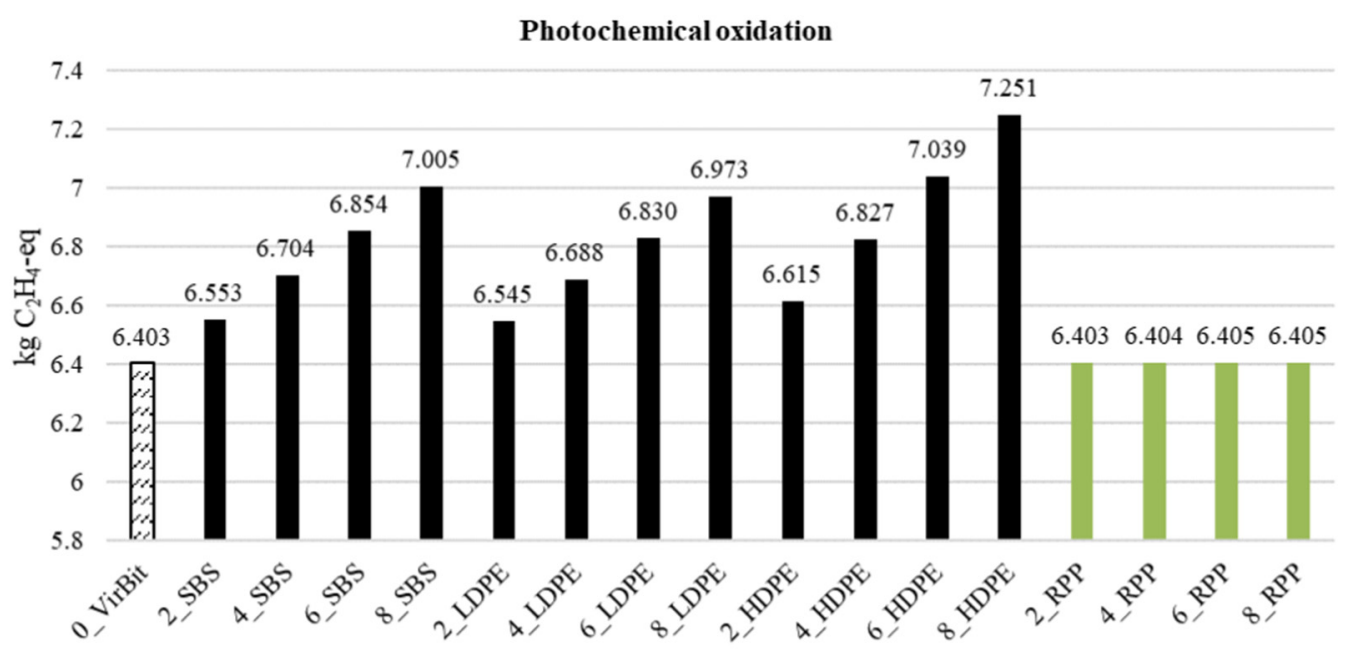

(e)

Fig. 4 (continued)

comparatively to asphalt mix VirgAggreg. This impact category is followed by Eu, which shows a maximum increase of roughly $15 \%$ in the impact score. The reason behind the remarkable increase in the scores of the impact category CC relies on the fact that it is particularly affected by the emissions associated with the production of electricity, whose consumption in the production of RRP is approx. 36 times greater than that required by the production of the same amount of virgin aggregates.

Finally, the results presented above for the impact category CC were benchmarked with those reported by the existing literature involving the use of recycled materials in road pavements, and for which the data and reported results allow for a comparison. Fig. 6 shows that the asphalt mixes considered in the present study resulted in higher GHG emissions than those corresponding to the cellulose-reinforced and end-of-life tyre fiber-reinforced asphalt mixes reported by Landi et al. (2020) as well as those incorporating crumb rubber and RAP reported by Farina et al. (2017). Nevertheless, the results of most of the asphalt mixes studied are within the same order the magnitude. Therefore, they can be considered plausible given the existing differences in the system boundaries, alternative materials, data quality, waste management system, assumptions and the geographical, temporal and technical contexts, all of which possibly avoiding a linear and direct comparison.

\subsection{Scenario analysis}

The relative variation of the impact category scores related to the production of RPP according to the two alternative scenarios in relation to those of the base scenario is displayed in Table 7. Positive relative values mean that the alternative scenario improves the environmental performance of the base scenario while negative values represent a deterioration.

The results presented in Table 7 corroborate the initial expected outcome that accounting for the transportation of the sorted plastic from the "sorting-only facility" to the "shredding and extruding-only facility" has a negative influence in the environmental performance of the recycling process. The most affected impact category is by far the OD, whose impact scores are expected to increase by $1740 \%$ in the AS2. On the contrary, the impact category $\mathrm{CC}$ is the least affected, registering relative increases in the scores that exceed $2 \%$ in the AS2.

\section{Discussion}

The LCA analysis carried out in this study evidenced the impacts of different methodologies for incorporating recycled waste plastics in asphalt mixes; specifically, a wet and a dry method were evaluated. The 
wet method (using waste plastic as a replacement for virgin polymers in bitumen) is easier to implement and generates less issues on the overall durability of the final PMB. On the other hand, the amount of waste plastic that can be recycled according to the wet method is limited, being this a small percentage of the bitumen, which already accounts for a small percentage of the entire asphalt mix. For a one-lane, 1-km road, the amount of recycled plastic is less than $1.5 \mathrm{t}$ (i.e. $8 \%$ of polymer loading), though a more realistic estimate would expect recycling less than $500 \mathrm{~kg}$ of plastics due to the drawbacks already discussed in the previous sections and commonly acknowledged when too much recycled plastic (i.e. more than 4\%) is incorporated in PMB (i.e. separation and storage stability issues and excessive brittleness). This analysis shows that recycling PE plastics and using the wet method can be beneficial for the environment by reducing the greenhouse gas (GHG) emissions up to approx. 16\%; this comes in addition to environmental savings on acidification, eutrophication and photochemical oxidation. If a consistent and controlled source of recycled PE plastics can be secured for road applications (i.e. a "road-grade" type of plastic), the substitution of recycled PE for common polymers has proven to be environmentally viable. Considering the 24,800 t of waste LDPE produced in Victoria annually and a recycling rate of approx. $500 \mathrm{~kg}$ for $1 \mathrm{~km}$ of road (one lane) using the wet method, then approx. $49,600 \mathrm{~km}$ (one lane) or $24,800 \mathrm{~km}$ (two lanes) of roads would need to be resurfaced using recycled plastics to consume the total waste LDPE generated over one year. Currently, there are approx. 200,000 km of roads in Victoria (two or more lanes) with more than $85 \%$ classified as local or minor arterials and the

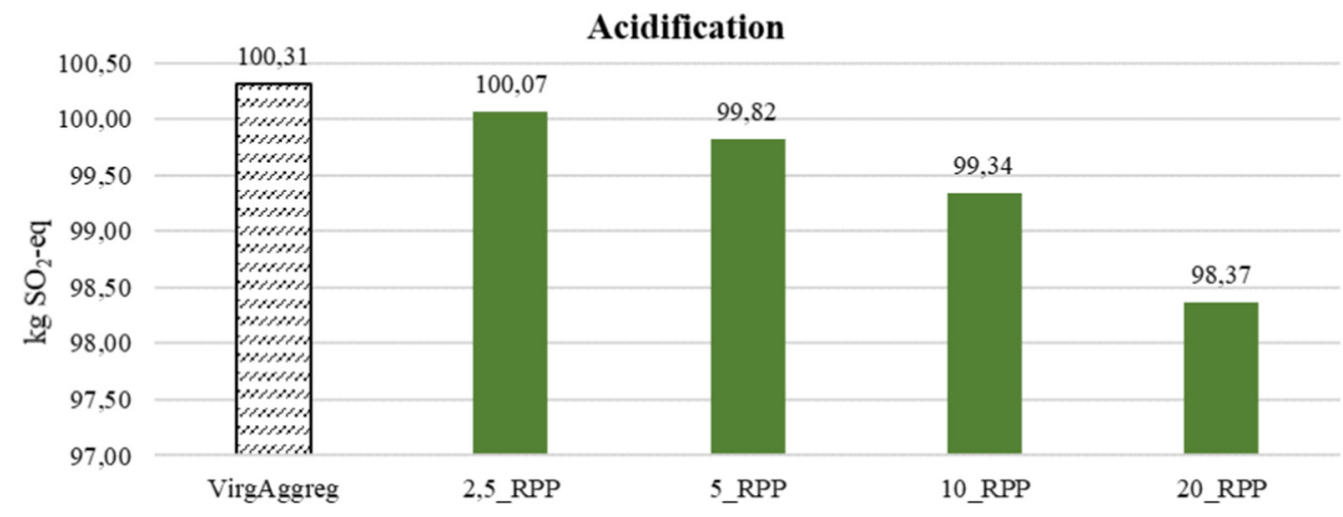

(a)

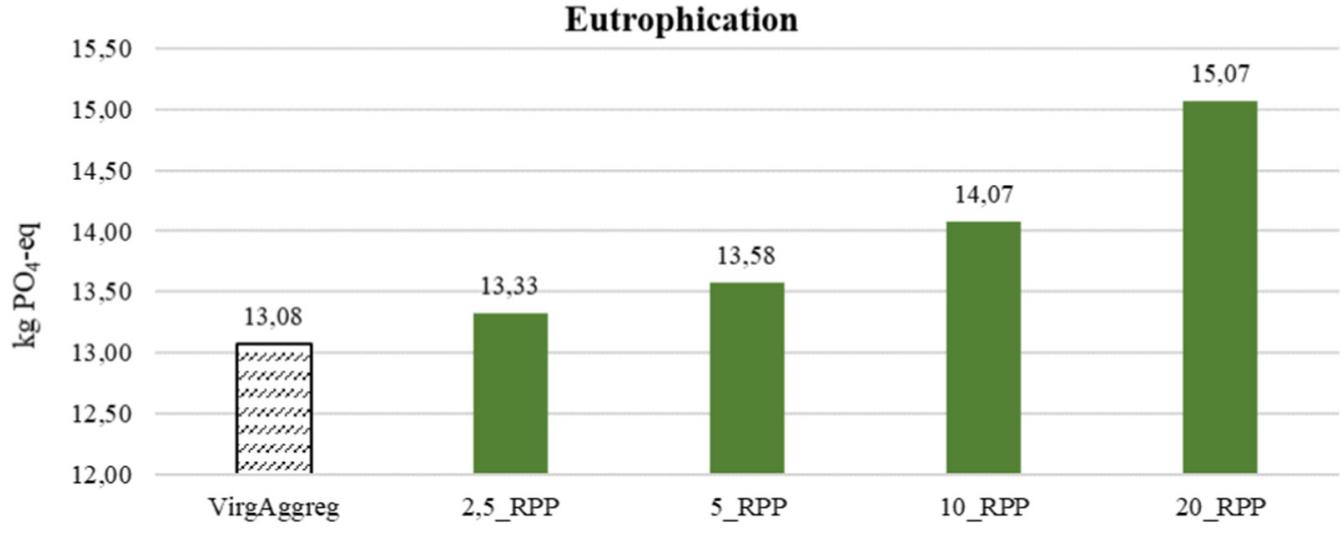

(b)

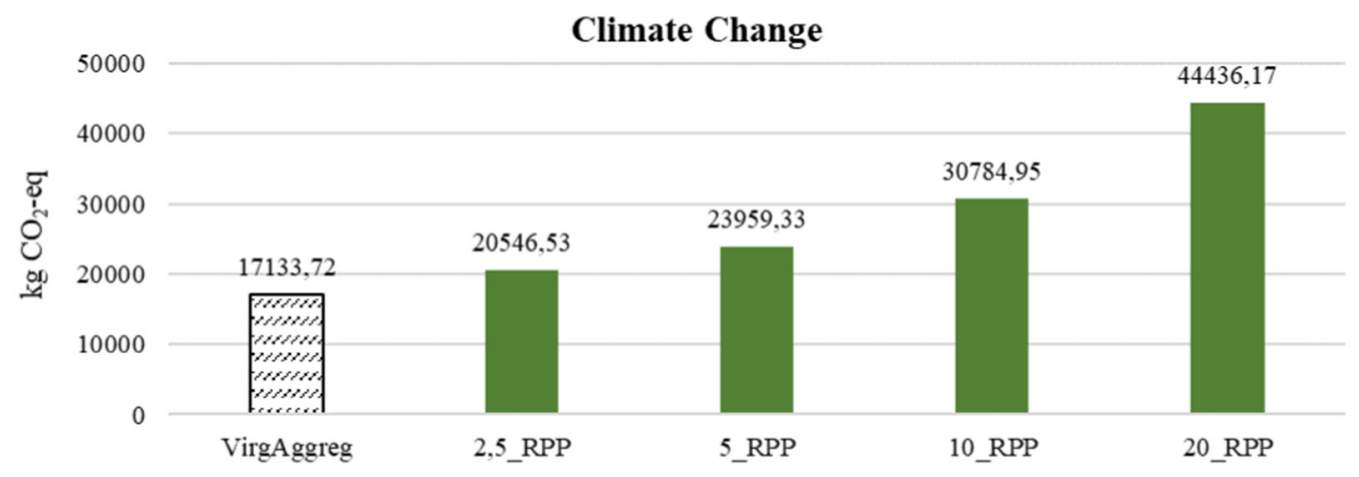

(c)

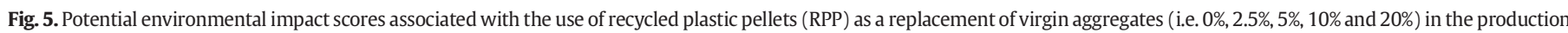
of asphalt mixes applied in the surface layer of the pavement presented in Table 1. (Key: VirAggreg- virgin aggregate; RPP- recycled plastic pallets). 
Ozone depletion

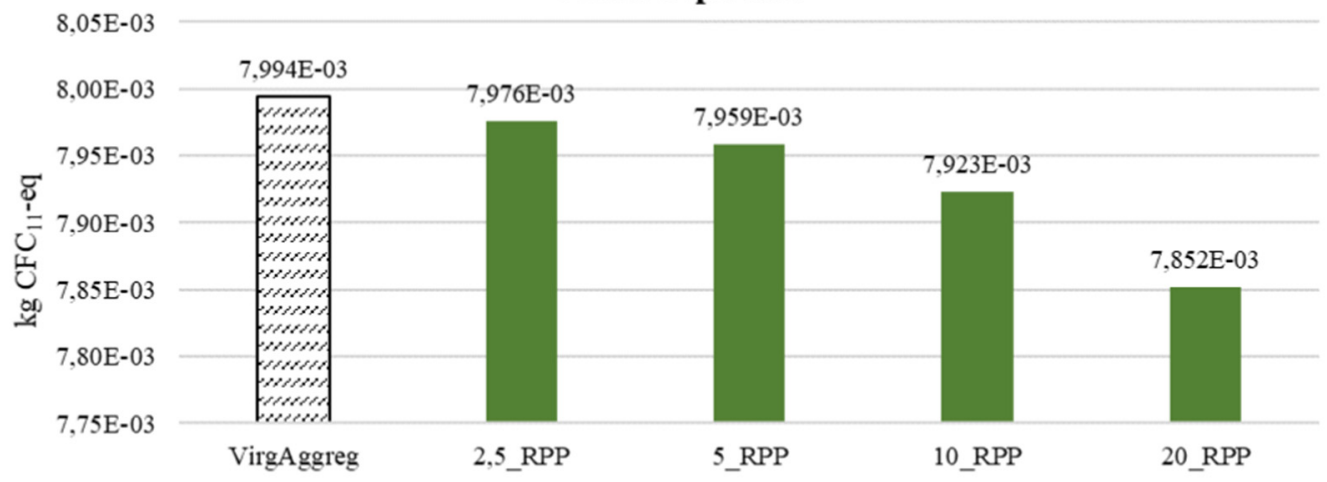

(d)

Photochemical oxidation

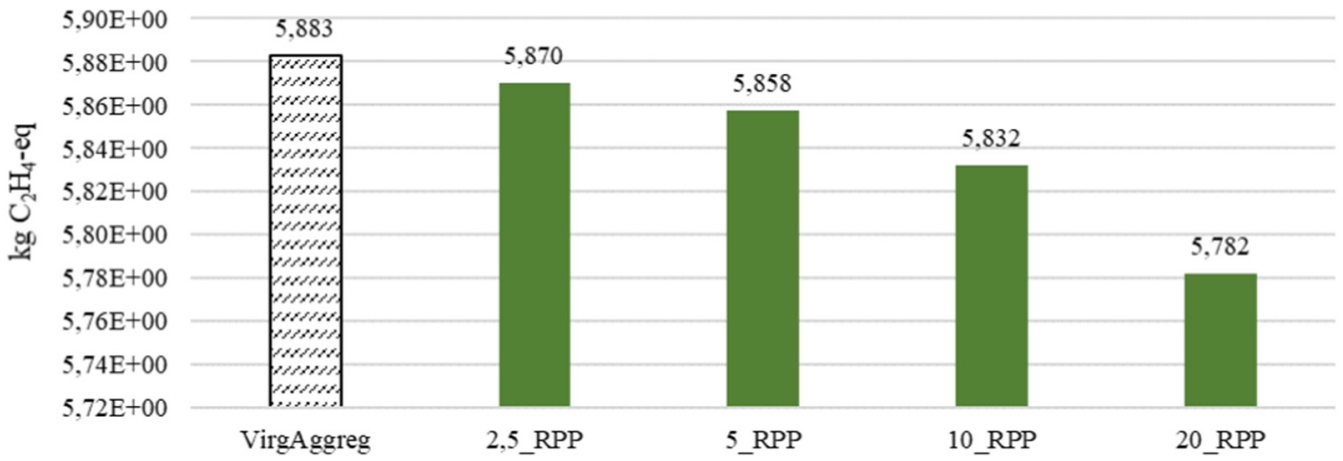

(e)

Fig. 5 (continued).

remaining part (approx. 23,000 km) as freeways and main arterials. Using recycled plastics with the wet method on minor/local council roads would suffice for the annual reuse of locally-recycled LDPE waste.

Conversely, the dry method consumes a much larger quantity of recycled plastic although both its durability (i.e. asphalt durability when including RPP in the mix) and environmental benefits are diminished. Asphalt durability can indeed suffer from the lack of adhesion between the plastic aggregate and the bitumen. Specifically, the GHG emissions increase up to $160 \%$ when $20 \%$ RPP is included in the mix as a replacement of virgin quarry aggregate; the other impact scores all show environmental betterments but Eutrophication. The increase of $\mathrm{CC}$ and $\mathrm{Eu}$ is a consequence of the greater energy demand

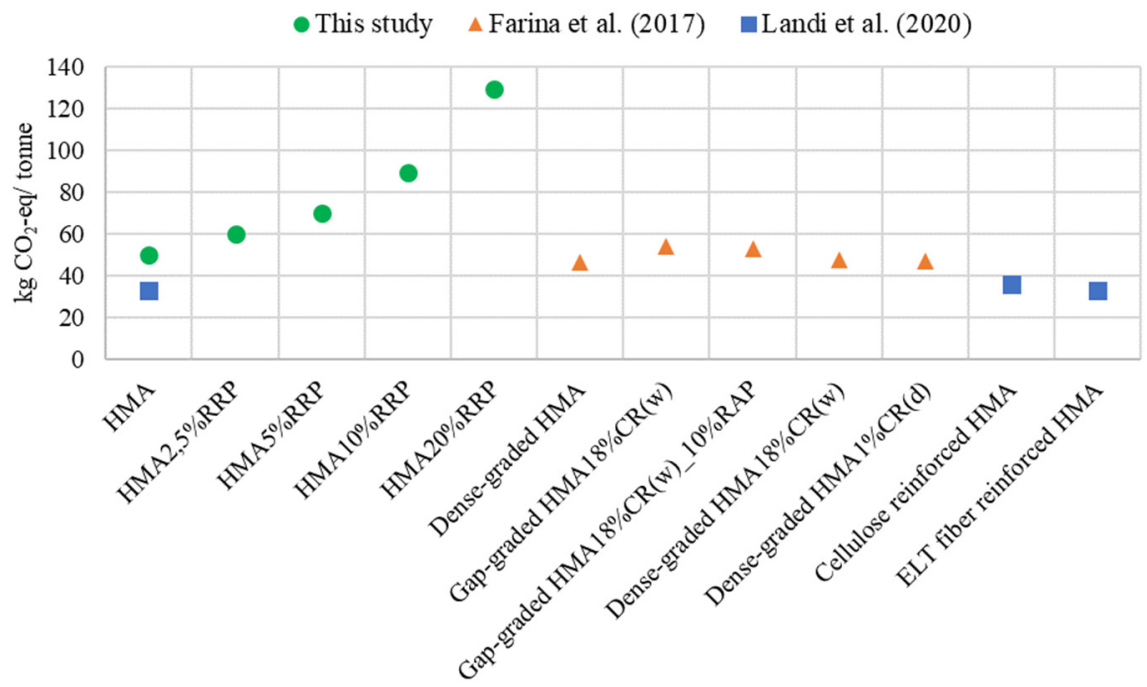

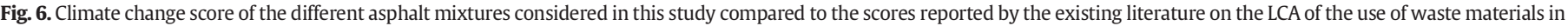

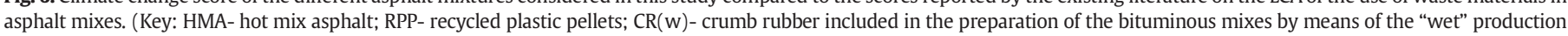
process; RAP- recycled asphalt pavement; CR(d)- crumb rubber included in the preparation of the bituminous mixes by means of the "dry" production process; ELT- end of life tyres). 
Table 7

Relative variation of the impact category scores of the two alternative scenarios in relation to those of the base scenario.

\begin{tabular}{lcr}
\hline Impact category & AS1 & \multicolumn{1}{c}{ AS2 } \\
\hline AC & $-26 \%$ & $-116 \%$ \\
Eu & $-4 \%$ & $-16 \%$ \\
CC & $-0.46 \%$ & $-2 \%$ \\
OD & $-390 \%$ & $-1740 \%$ \\
PO & $-32 \%$ & $-141 \%$ \\
\hline
\end{tabular}

Key: Ac- acidification; Eu- eutrophication; CC- climate change; OD- ozone layer depletion; PO- photochemical oxidation.

(electricity) required to produce RPP. However, it should be noted that replacing virgin aggregate with $2.5 \%$ RPP has the potential to consume approx. $8.5 \mathrm{t}$ of waste plastics for $1 \mathrm{~km}$ (one lane) of road, without significantly increasing the amount of emissions being generated. Considering the 22,000 t per year of waste PP in Victoria, approx. $2588 \mathrm{~km}$ (one lane) or $1294 \mathrm{~km}$ (two lanes) of roads would be sufficient for locally recycling the total annual production of waste PP in the state. It is worth noting that several alternatives exist for recycling plastics, and not all the plastics generated in Victoria are expected to be reused in roads.

Finally, the LCA analysis shows the sensitivity of the results to alternative scenarios; in particular, as expected, increasing the distances between the processing facilities and the plants reduces the environmental savings associated with the respective technology (i.e. wet or dry). This fosters the idea of 1 ) 'recycling locally' hence reducing the movement of recycled plastics intrastate and interstate, and 2) promoting the government infrastructure funding to recycling centres that can handle all the recycling processes within the same facility.

\section{Conclusions and future work}

The present study investigates the impacts of recycling waste plastics in asphalt by using primary data from local processing facilities in Victoria, Australia. Based on the outcomes of the LCA analysis and for the conditions considered in the study, the following conclusions can be drawn:

- Recycling soft plastics as a polymer for bitumen modification delivers significant environmental benefits compared to its counterpart of using virgin polymers. Even if the total amount of recycled plastics is a small percentage of the total asphalt mix, the wet method has proven to be environmentally friendly (fewer emissions), cost effective (RPP is cheaper than virgin polymers) and efficient in improving bitumen performance. Specifically, a reduction of up to $10.2 \%$ of $\mathrm{CO}_{2}$-eq emissions was observed when replacing $8 \%$ of virgin polyethylene with the same amount of RPP; the environmental benefit becomes even more evident $(-15.6 \%)$ when replacing SBS with RPP. All the environmental indicators were generally improved by the use of RPP.

- Recycling rigid plastics as an aggregate replacement in asphalt mixes has proven to just minimally benefit the environment. Their use at low percentages (i.e. $2.5 \%$ or less) could significantly increase the recycling rate without substantially harming the ecosystem ( $+19.9 \% \mathrm{CO}_{2}$-eq, $+1.9 \% \mathrm{PO}_{4}$-eq, $-0.24 \% \mathrm{SO}_{2}$-eq, $-0.34 \% \mathrm{CFC}_{11}$-eq and $-0.22 \% \mathrm{C}_{2} \mathrm{H}_{4}$-eq). More research is needed on evaluating the performance-related aspects of asphalt mixes comprising RPP as quarry aggregate replacement. In addition, the costs of RPP should also be considered as it could potentially be much higher than that of quarry aggregate, depending on the type of plastics being recycled.

Future work on this subject should investigate the overall problem of recycling plastics in roads by performing a multi-attribute analysis that considers costs and mechanical performance (durability) in addition to the environmental factors. It is expected that the type of plastics and mixing technology (i.e. wet or dry) to be used will depend on the classification of the road (i.e. traffic levels) and proximity to the reprocessing facility.

\section{Disclaimer}

The contents of this paper reflect the views of the authors, who are responsible for the facts and the accuracy of the data presented. The contents do not necessarily reflect the official views or policies of National Authorities. Any inclusion of manufacturer names, trade names or trademarks is for identification purposes only and is not to be considered an endorsement. Moreover, this paper does not constitute a standard, specification or regulation.

\section{CRediT authorship contribution statement}

J. Santos: Conceptualization, Formal analysis, Methodology, Writing - original draft, Writing - review \& editing. A. Pham: Conceptualization, Formal analysis, Methodology, Writing - original draft. P. Stasinopoulos: Conceptualization, Formal analysis, Methodology, Writing - original draft. F. Giustozzi: Conceptualization, Methodology, Writing - original draft, Writing - review \& editing, Project administration, Supervision.

\section{Declaration of competing interest}

No potential conflict of interest was reported by the authors.

\section{References}

Allacker, K., Mathieux, F., Pennington, D., Pant, R., 2017. The search for an appropriate end-of-life formula for the purpose of the European Commission environmental footprint initiative. Int. J. Life Cycle Assess. 22, 1441-1458. https://doi.org/10.1007/ s11367-016-1244-0.

Andersson-Sköld, Y., Johannesson, M., Gustafsson, M., Järlskog, I., Lithner, D., Maria, P., Strömvall, A., 2020. Microplastics from tyre and road wear: a literature review. The Swedish National Road and transport research institute (VTI), VTI rapport 1028A Available from. https://research.chalmers.se/en/publication/517097.

Andrady, 2017. The plastic in microplastics: a review. Mar. Pollut. Bull. 119 (1), 12-22 https://doi.org/10.1016/j.marpolbul.2017.01.082.

Aurangzeb, Q., Al-Qadi, I.L., Ozer, H., Yang, R., 2014. Hybrid life cycle assessment for asphalt mixtures with high RAP content. Resour. Conserv. Recycl. 83, 77-86. https:// doi.org/10.1016/j.resconrec.2013.12.004.

Bonicelli, A., Calvi, P., Martinez-Arguelles, G., Fuentes, L., Giustozzi, F., 2017. Experimental study on the use of rejuvenators and plastomeric polymers for improving durability of high RAP content asphalt mixtures. Constr. Build. Mater. 155, 37-44. https://doi. org/10.1016/j.conbuildmat.2017.08.013.

BRE, 2013. Product category rules (PCR) for type III environmental product declaration of construction products to EN 15804:2012. Available from. http://www.bre.co.uk/ filelibrary/Materials/BRE_EN_15804_PCR.PN514.pdf.

Bressi, S., Santos, J., Orešković, M., Losa, M., 2019. A comparative environmental impact analysis of asphalt mixtures containing crumb rubber and reclaimed asphalt pavement using life cycle assessment. International Journal of Pavement Engineering, 1-15 https://doi.org/10.1080/10298436.2019.1623404.

Department of Agriculture, Water and Environment, 2019. National waste policy action plan, Australian Government. Available from. https://www.environment.gov.au/protection/waste-resource-recovery/publications/national-waste-policy-action-plan.

European Commission - Joint Research Centre - Institute for Environment and Sustainability (EC-JCR-IES), 2010. International Reference Life Cycle Data System (ILCD) Handbook - General Guide for Life Cycle Assessment - Detailed Guidance. First Edition March 2010. EUR 24708 EN. Publications Office of the European Union Luxembourg https://eplca.jrc.ec.europa.eu/uploads/ILCD-Handbook-General-guidefor-LCA-DETAILED-GUIDANCE-12March2010-ISBN-fin-v1.0-EN.pdf.

Farina, A., Zanetti, M.C., Santagata, E., Blengini, G.A., 2017. Life cycle assessment applied to bituminous mixtures containing recycled materials: crumb rubber and reclaimed asphalt pavement. Resour. Conserv. Recycl. 117, 204-212. https://doi.org/10.1016/j. resconrec.2016.10.015.

Flynn, L., 1993. Recycled plastic finds home in asphalt binder. Roads \& Bridges 31 (3), 41-47.

Giustozzi, F., Crispino, M., Flintsch, G., 2012. Multi-attribute life cycle assessment of preventive maintenance treatments on road pavements for achieving environmental sustainability. Int. J. Life Cycle Assess. 17 (4), 409-419. https://doi.org/10.1007/ s11367-011-0375-6.

Giustozzi, F., Crispino, M., Toraldo, E., Mariani, E., 2019. Mix design of polymer-modified and fiber-reinforced warm-mix asphalts with high amount of reclaimed asphalt pavement: achieving sustainable and high-performing pavements. Transportation 
Research Record: Journal of the Transportation Research Board 2523 (1), 3-10. https://doi.org/10.3141/2523-01.

Greendelta, 2016. openLCA. Available from. www.openlca.org.

Guinee, J., Gorree, M., Heijungs, R., Huppes, G., Kleijn, R., de Koning, A., van Oers, L. Sleeswijk, A., Suh, S., Udo de Haes, H., de Bruijn, H., van Duin, R., Huijbregts, M., 2002. Handbook on Lifecycle Assessment. Operational Guide to the ISO Standards. I: LCA in Perspective. IIa: Guide. IIb: Operational Annex. III: Scientific Background. Kluwer Academic Publishers, Dordrecht.

Heikkilä, P.R., Väänänen, V., Hämeilä, M., Linnainmaa, K., 2003. Mutagenicity of bitumen and asphalt fumes. Toxicol. in Vitro 17 (4), 403-412. https://doi.org/10.1016/ S0887-2333(03)00045-6.

Hınıslığlu, S., Ağar, E., 2004. Use of waste high density polyethylene as bitumen modifier in asphalt concrete mix. Mater. Lett. 58 (3-4), 267-271. https://doi.org/10.1016/ S0167-577X(03)00458-0.

Ho, S., Church, R., Klassen, K., Law, B., MacLeod, D., Zanzotto, L., 2006. Study of recycled polyethylene materials as asphalt modifiers. Can. J. Civ. Eng. 33 (8), 968-981. https://doi.org/10.1139/106-044.

Infrastructure Victoria, 2019. Recycling and resource recovery infrastructure. Evidence base report - October 2019. Available from. https://www.infrastructurevictoria. com.au/project/advice-on-waste-infrastructure-in-victoria/.

ISO, 2006a. ISO International Standard 14040: Environmental Management - Life Cycle Assessment - Principles and Framework. International Organization for Standardization, Geneva, Switzerland.

ISO, 2006b. ISO International Standard 14044: Environmental Management - Life Cycle Assessment - Requirements and Guidelines. International Organization for Standardization, Geneva, Switzerland.

Joohari, I.B., Giustozzi, F., 2020. Chemical and high-temperature rheological properties of recycled plastics-polymer modified hybrid bitumen. J. Clean. Prod. 276, 123064 https://doi.org/10.1016/j.jclepro.2020.123064.

Landi, D., Marconi, M., Bocci, E., Germani, M., 2020. Comparative life cycle assessment of standard, cellulose-reinforced and end of life tires fiber-reinforced hot mix asphal mixtures. J. Clean. Prod. 248, 119295. https://doi.org/10.1016/j.jclepro.2019.119295.

Li, J., Xiao, F., Zhang, L., Amirkhanian, S., 2019. Life cycle assessment and life cycle cost analysis of recycled solid waste materials in highway pavement: a review. J. Clean. Prod. 233 (1), 1182-1206. https://doi.org/10.1016/j.jclepro.2019.06.061.

Lindberg, H.K., Väänänen, V., Järventaus, H., Suhonen, S., Nygren, J., Hämeilä, M. Valtonen, J., Heikkilä, P., Norppa, H., 2008. Genotoxic effects of fumes from as phalt modified with waste plastic and tall oil pitch. Mutation Research/Genetic Toxicology and Environmental Mutagenesis 653 (1-2), 82-90. https://doi.org/ 10.1016/j.mrgentox.2008.03.009.

Little, D.N., 1993. Enhancement of asphalt concrete mixtures to meet structural requirements through the addition of recycled polyethylene. In: Waller, H. (Ed.), Use of Waste Materials in Hot-Mix Asphalt. vol. 1993. ASTM International, West Conshohocken, PA, pp. 210-230.

Locock, K., 2017. The Recycled Plastics Market: Global Analysis and Trends. CSIRO Australia.
Nizamuddin, S., Jamal, M., Gravina, R., Giustozzi, F., 2020. Recycled plastic as bitumen modifier: the role of recycled linear low-density polyethylene in the modification of physical, chemical and rheological properties of bitumen. J. Clean. Prod. 266, 121988. https://doi.org/10.1016/j.jclepro.2020.121988.

Praticò, F.G., Giunta, M., Mistretta, M., Gulotta, T.M., 2020. Energy and environmental life cycle assessment of sustainable pavement materials and technologies for urban roads. Sustainability 12 (2), 704. https://doi.org/10.3390/su12020704.

Rahman, M.T., Mohajerani, A., Giustozzi, F., 2020. Recycling of waste materials for asphalt concrete and bitumen: a review. Materials 13 (7), 1495. https://doi.org/10.3390/ ma13071495.

Renouf, M.A., Grant, T., Sevenster, M., Ridoutt, B., Ximenes, F., Logie, J., Bengtsson, J., Cowie, A., Lane, J., 2015. Best Practice Guide to Life Cycle Impact Assessment in Australia. Australian Life Cycle Assessment Society Available from. http://www.auslci.com.au/ Documents/Best_Practice_Guide_V2_Draft_for_Consultation.pdf.

Rodríguez-Fernández I. Cavalli, M.C. Poulikakos, L, Bueno, M., 2020. Recyclability of asphalt mixtures with crumb rubber incorporated by dry process: a laboratory investigation. Materials 13 (12), 2870. https://doi.org/10.3390/ma13122870.

Roychand, R., Pramanik, B.K., 2020. Identification of micro-plastics in Australian road dust. Journal of Environmental Chemical Engineering 8 (1), 103647. https://doi.org/ 10.1016/j.jece.2019.103647.

Santos, J., Bryce, J., Flintsch, G., Ferreira, A., Diefenderfer, B., 2015. A life cycle assessment of in-place recycling and conventional pavement construction and maintenance practices. Struct. Infrastruct. Eng. 11 (9), 1199-1217. https://doi.org/10.1080/ 15732479.2014 .945095$.

Santos, J., Cerezo, V., Soudani, K., Bressi, S., 2018. A comparative life cycle assessment of hot mixes asphalt containing bituminous binder modified with waste and virgin polymer. Procedia CIRP 69, 194-199. https://doi.org/10.1016/j.procir.2017.11.046.

Schrijvers, D., Loubet, P., Sonnemann, G., 2020. Archetypes of goal and scope definitions for consistent allocation in LCA. Sustainability 12, 5587. https://doi.org/10.3390/ su12145587.

Schroeder, L., 1994. The use of recycled materials in highway construction. Federal Highway Administration 58 (2), 32-41.

Singh, P., Tophel, A., Swamy, A.K., 2017. Properties of asphalt binder and asphalt concrete containing waste polyethylene. Pet. Sci. Technol. 35 (5), 495-500. https://doi.org/ 10.1080/10916466.2016.1265559.

Wang, T., Xiao, F.-, Zhu, X., Huang, B., Wang, J., Amirkhanian, S., 2018. Energy consumption and environmental impact of rubberized asphalt pavement. J. Clean. Prod. 180, 139-158. https://doi.org/10.1016/j.jclepro.2018.01.086

White, G., Reid, G., 2018. Recycled waste plastic for extending and modifying asphalt binders. 8th Symposium on Pavement Surface Characteristics (SURF 2018), Brisbane, Queensland, Australia, pp. 2-4.

Zhao, Z., Xiao, F., Amirkhanian, S., 2020. Recent applications of waste solid materials in pavement engineering. Waste Manag. 108, 78-105. https://doi.org/10.1016/j. wasman.2020.04.024

Zhu, J., Birgisson, B., Kringos, N., 2014. Polymer modification of bitumen: advances and challenges. Eur. Polym. J. 54, 18-38. https://doi.org/10.1016/j.eurpolymj.2014.02.005. 